\title{
Validation of a newly developed multi-dimensional instrument to assess maternal perceptions of the quality of institutional postnatal care services in Sri Lanka
}

\author{
Sashimali Wickramasinghe ${ }^{1 *}$, Wasantha Gunathunga ${ }^{1}$, Nilmini Hemachandra ${ }^{2}$ \\ ${ }^{1}$ Department of Community Medicine, Faculty of Medicine, University of Colombo, Sri Lanka; ${ }^{2}$ World \\ Health Organization Country Office, Sri Lanka \\ ${ }^{*}$ Correspondence: Sashimali2004@yahoo.com \\ (DD https://orcid.org/0000-0003-4216-4233 \\ DOI: https://doi.org/10.4038/jccpsl.v25i2.8183
}

Received on: 24 October 2018

Accepted on: 29 May 2019

\begin{abstract}
Introduction: Postnatal period is an important period during which both mother and the newborn adjust to the new environment. High quality services should be provided during this period in order to prevent adverse health outcomes. Patients' perception of the care received by them is considered an important attribute in the assessment and improvement of quality of health care. However, this should be assessed using a valid and reliable instrument.

Objectives: To assess the psychometric properties of a newly developed instrument to assess the mothers' perception of the quality of institutional postnatal care in Sri Lanka

Methods: The instrument was validated among 200 mothers who had undergone normal vaginal delivery in Colombo North Teaching Hospital and were in the immediate postnatal period. The factor structure of the instrument, its internal consistency and test retest reliability were assessed as main outcomes.

Results: Following exploratory factor analysis, the instrument consisted of 23 items. Three main domains identified were interpersonal care, technical care and information, and ward facilities and cleanliness. The threefactor model identified was able to explain $58.9 \%$ of the total variance of the scale. The Cronbach's alpha value for the total scale was 0.94. The Spearman's rank correlation coefficient value for the test retest reliability was 0.94 .

Conclusions: The instrument developed for assessment of maternal perception of the quality of postnatal care reported satisfactory level of validity and reliability, thus recommended to be used for improving care provision.
\end{abstract}

Keywords: client-perceived quality, exploratory factor analysis, validation, postnatal care quality, reliability assessment 


\section{Introduction}

Postnatal period, or the first six weeks following delivery, is important for both mother and the newborn for many reasons including an increased risk of maternal and newborn mortality (1-2). Around three quarters of neonatal and maternal deaths take place in the first week following delivery, with up to half taking place in the first 24 hours (1-2). Therefore, improving the quality of care provided at hospital during this period is vital for reducing morbidity and mortality among them.

Improving the quality of care begins with assessment of the current quality (3). Client-perceived quality of care is increasingly being considered as an important component in this assessment (4-7) and is defined as 'subjective and dynamic perception of the extent to which expected health care is received' (8-9). Mother's perception of the care received immediately after the delivery of baby may influence her health seeking behaviour in the future (10). Consequently, she may decide not to utilise the same service in case of an emergency, if she perceives the care received as sub-optimal. Therefore, assessing mothers' perception on the hospital care received and improving it accordingly to suit their needs is a timely requirement.

In Sri Lanka, about $94.6 \%$ of mothers receive postnatal care through government institutions (11). Regular monitoring of this care through maternal perception is an easy and swift measure to assess its quality, so that healthcare providers could receive valuable feedback to meet mothers' expectations and to ensure their satisfaction.

Client perceptions are assessed using both qualitative and quantitative methods. Qualitative methods are useful to understand the concepts behind maternal perceptions, whereas quantitative methods are useful to quantify their reactions (12). Though there are many instruments available for this purpose, only a few have undergone validity and reliability assessments (4). Validity and reliability are important attributes of an instrument that will determine the usability of the results of the instrument to make policy decisions. Further, the instruments already validated in the local and international literature on maternal perceptions were not specific to assess postnatal care. An instrument that has been validated in Burkina Faso and Vietnam assesses the maternal care in general (8), while an instrument that has been validated in Sri Lanka assesses the antenatal care (9). Thus, in the absence of a valid and reliable instrument to assess the maternal perception on the quality of institutional post-natal care in Sri Lanka, the authors developed a new instrument to measure this concept. This paper presents its assessment of validity and reliability. Availability of a valid and reliable instrument would enable the health staff to utilize it to improve their performance during this critical period. This information would be valuable to reform the care to make it more patient centred.

\section{Methods}

The instrument was developed by the investigators using a stringent process, which included defining the concept, generation of an item pool, determination of the measurement format, selection of items, pre-testing and testing for psychometric properties (13). The developed instrument had 28 items, which was then subjected to assessment of its construct validity via exploratory factor analysis (EFA). Reliability was assessed through test retest reliability and internal consistency assessment.

Data for assessing construct validity were collected in the three obstetric units of Colombo North Teaching Hospital. The study population was mothers who had undergone normal vaginal delivery and delivered live healthy singleton babies in the study setting. Mothers or babies with unstable health conditions at the time of interview, mothers who are unable to converse in Sinhala language and mothers for whom the discharge procedures have not been completed at the time of the interview were excluded.

The sample size was decided based on different recommendations that were found in literature in relation to sample size determination for EFA. Some experts suggest that five to ten participants per item in the instrument is considered adequate, while some have suggested cut-offs based on the total number of participants (14). Based on the former method and as the number of items in the finalized instrument was 28 , it was decided to recruit 200 participants for the study. Consecutive sampling technique was used to recruit participants from each ward until the required sample size was collected. Data were collected from 1 st November 2016 to $13^{\text {th }}$ December 2016 by three trained female pre-intern medical graduates. Data collection was carried out once all the discharge procedures have been completed for each selected 
patient. Informed written consent was obtained prior to data collection.

\section{Data analysis}

The data entry and EFA were conducted by the PI using Statistical Package for Social Sciences (SPSS) version 21. Prior to EFA, data were initially screened for the suitability for factor analysis. Reliability of the instrument was ensured by assessing the internal consistency (15). A Cronbach's alpha score of more than 0.7 was considered as adequate (16). Test retest reliability was assessed by re-assessing 30 participants 2 weeks following the first assessment. A value of 0.7 or greater was considered as satisfactory reliability (17).

\section{Results}

All 200 mothers responded to the questionnaire. The mean age of the sample was 28.9 years $(\mathrm{SD}=4.8)$. Majority of the mothers were Sinhalese Buddhists and belonged to the 20-34 age group. The basic information of the study population is given in Table 1 .

Prior to conducting the EFA, data were screened for their suitability for conducting an EFA. Univariate normality was assessed by computing histograms and standardized skewness and kurtosis for all the items. The acceptable range were taken as -1.96 to +1.96 (18). Except for two items, all the other items had skewness values in the acceptable range.

Factorability was assessed by observing inter-item correlation matrix, anti-image matrix and measures of sampling adequacy. Correlation matrix revealed that five items had a high number of correlations below 0.3 . Therefore, they were removed from the item list, one by one. Thus, the final instrument subjected to EFA had 23 items. All the diagonals on the anti-image correlation matrix were above 0.5 . Bartlett's test of sphericity was significant, indicating that the correlation matrix was significantly different from the identity matrix (Chi-squared value $=3547.9 ; \mathrm{p}<0.001$ ). The Kaiser-Meyer-Olkin (KMO) measure, which is an index for comparing the magnitude of the observed correlation matrix to the magnitude of the partial correlation matrix, was 0.917 , which was greater than the recommended value for factor analysis $(>0.5)$. All these measures established factorability and sampling adequacy.
Table 1. Distribution of the study participants by socio-demographic and pregnancy related characteristics $(N=200)$

\begin{tabular}{lrr}
\hline Variable & No. & $\%$ \\
\hline Age in years & & \\
$<20$ & 4 & 2.0 \\
$20-34$ & 176 & 88.0 \\
$\geq 35$ & 20 & 10.0 \\
\hline Ethnicity & & \\
Sinhala & 197 & 98.5 \\
Muslim & 3 & 1.5 \\
\hline Religion & & \\
Buddhist & 161 & 80.5 \\
Catholic & 36 & 18.0 \\
Islam & 3 & 1.5 \\
\hline
\end{tabular}

\section{Highest level of education}

Grade 1-5

6.0

Grade 6-11

16.0

Passed GCE (O/L)

32.0

Passed GCE (AL) ${ }^{2}$

38.0

Graduate

16

8.0

\section{Occupation}

Unemployed

Skilled manual

$160 \quad 80.0$

Clerical

4

2.0

Professional

12

6.0

Monthly income

\begin{tabular}{lll}
$<30,750$ & 48 & 24.0 \\
$30,750-40,000$ & 64 & 32.0 \\
$40,001-50,000$ & 52 & 26.0 \\
$>50,000$ & 36 & 18.0 \\
\hline
\end{tabular}

\section{Parity (Current pregnancy)}

P1

76

$\mathrm{P} 2-\mathrm{P} 4$

124

62.0
${ }^{1}$ General Certificate of Education (Ordinary Level) ${ }^{2}$ General Certificate of Education (Advanced Level) 
Subsequently, EFA was carried out using principal component analysis with varimax rotation, as this combination gave the best factor structure. The number of factors to be retained was decided based on Eigen values and examining scree plots. Four factors had an Eigen value over one while scree plot analysis suggested a three-factor solution (Figure 1). As the qualitative data analysis during development of the instrument suggested five themes, EFA was run three times, setting the number of factors to be ex-tracted manually, as three, four and five. The one with three factors extracted was selected, as it gave the best factor structure, with all items loading to one of the three factors with a factor coefficient of more than 0.45 . This value was considered as the cut-off value for factor loadings (14). There were only a few crossloading items while each factor had more than three items loaded. These three factors explained $58.9 \%$ of the total variance.
Scree Plot

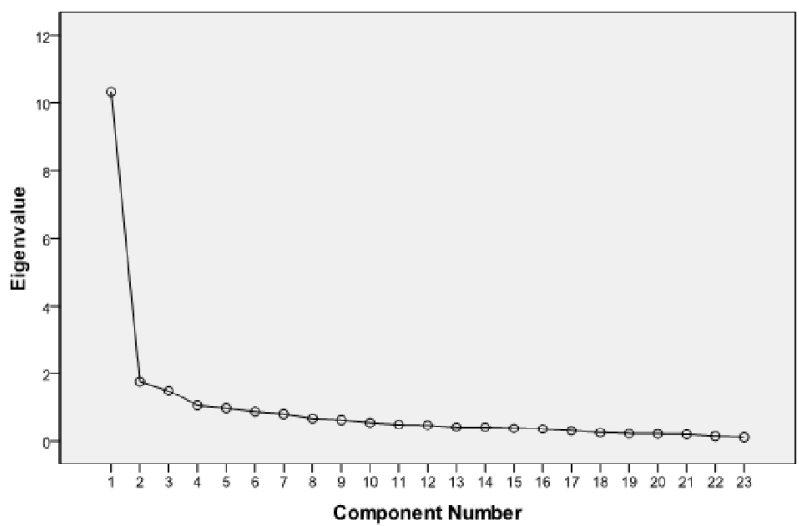

Figure 1. Scree plot result of exploratory factor analysis of the instrument

Final factor loadings for each domain are presented in Table 2. Factors were named by analysing the items under each factor or domain. Factor I named as 'technical care and information' domain had an eigen value of 10.31 and explained $44.8 \%$ of the variance.

Table 2. Final factor loadings of the items assigned to each domain in $\operatorname{EFA}(\mathrm{N}=\mathbf{2 0 0})$

\begin{tabular}{|c|c|}
\hline Factor/Item & Factor loading \\
\hline \multicolumn{2}{|l|}{ Technical care and Information } \\
\hline 1. Help given by the health workers to take care of your baby & 0.82 \\
\hline 2. Information given on caring for the baby & 0.76 \\
\hline 3. Help given by the health workers to take care of yourself & 0.74 \\
\hline 4. $\mathrm{HCWs}^{*}$ skills to care for you & 0.74 \\
\hline 5. Help given by the health workers for breast feeding & 0.71 \\
\hline 6. Adequacy of information given to clarify your issues & 0.69 \\
\hline 7. Information given on breast feeding & 0.68 \\
\hline 8. Information given on danger signs & 0.62 \\
\hline 9. HCWs skills to take care of the baby & 0.49 \\
\hline \multicolumn{2}{|l|}{ Interpersonal care } \\
\hline 1. Friendliness shown by the HCWs & 0.76 \\
\hline 2. Concern shown for pain relief during the postpartum period & 0.76 \\
\hline 3. Promptness of the attention shown to you by the HCWs & 0.75 \\
\hline 4. Patience shown towards you by the HCWs & 0.68 \\
\hline 5. Willingness to discuss about your concerns & 0.65 \\
\hline 6. Way the HCWs treated your family members & 0.49 \\
\hline 7. Respect given for privacy & 0.46 \\
\hline \multicolumn{2}{|l|}{ Ward facilities and cleanliness } \\
\hline 1. Adequacy of space in the postnatal ward & 0.84 \\
\hline 2. Adequacy of facilities in the ward & 0.78 \\
\hline 3. Cleanliness of the ward & 0.63 \\
\hline 4. Adequacy of labour room beds & 0.60 \\
\hline 5. Cleanliness of the toilets and washrooms & 0.59 \\
\hline 6. Ability to some rest in the postnatal ward & 0.46 \\
\hline 7. Adequacy of the number of healthcare workers & 0.20 \\
\hline
\end{tabular}


Factor II named as 'interpersonal care' domain had an eigen value of 1.76 and explained $7.66 \%$ of the variance. Factor III named as 'ward facilities and cleanliness' domain had an eigen value of 1.48 and explained $6.45 \%$ of the total variance.

Internal consistency of the instrument was assessed by computing Cronbach's alpha value for the total scale and its domains. The Cronbach's alpha values for the total scale and all domains exceeded Nunnally's criteria of 0.7 , establishing internal consistency. The Spearman's correlation coefficients for all domains and the total score were above 0.7 , indicating good test retest reliability (Table 3 ).

\section{Table 3. Cronbach's alpha values and Spearman's rank correlation coefficient values for each domain of the instrument} $(\mathrm{N}=\mathbf{2 0 0})$

\begin{tabular}{lcc}
\hline Domain & $\begin{array}{c}\text { Cronbach's } \\
\text { alpha value }\end{array}$ & $\begin{array}{c}\text { Spearman's } \\
\text { rank } \\
\text { correlation } \\
\text { coefficient }\end{array}$ \\
\hline Interpersonal care & 0.88 & 0.97 \\
$\begin{array}{l}\text { Technical care and } \\
\text { Information }\end{array}$ & 0.91 & 0.87 \\
$\begin{array}{l}\text { Ward facilities and } \\
\text { Cleanliness }\end{array}$ & 0.82 & 0.90 \\
\hline Total Scale & $\mathbf{0 . 9 4}$ & $\mathbf{0 . 9 4}$ \\
\hline
\end{tabular}

\section{Discussion}

To the best of the authors'knowledge, this is the first validated instrument to assess maternal perceptions of the quality of postnatal care provided by institutions in Sri Lanka. The instrument demonstrated an adequate level of validity and reliability, which was enabled by following a stringent process during the development phase, as proposed in literature $(17,19-20)$. Instruments without adequate psychometric properties will invariably deliver misleading information detrimental for policy planning and decision making (4).

The non-judgmental validity of the current instrument was established by conducting EFA, which serves two purposes. It can be used for selection of items during the development phase of an instrument as well to test its psychometric properties. It is used frequently as a measure of construct validity to assess the relationship between the construct under study and other theoretically related constructs. It is suited for concepts such as client perceived quality, which is of multi-dimensional nature. There are no known validated instruments that assess client perceptions of institutional postnatal care, however, many instruments assessing client perception or satisfaction on other aspects have been validated using similar techniques (8-9).

Three factors were extracted by the current analysis namely, interpersonal care; technical care and information; and ward facilities and cleanliness. There is no consensus on the number of dimensions for client perceptions. Literature provides a variety of dimensions ranging from one to fourteen, with the average number being six. Comparison of the instruments used to assess client perceptions demonstrates that most of them have three to five domains. Considered together, the domains assess the characteristics of healthcare delivery, health institution and health personnel, however the EFA has produced different domains in different studies. This may be attributed to the fact that factor extraction is based on characteristics of the study population and properties of the study design (4).

Most of the studies evaluated had a domain in relation to financial and geographical accessibility $(8-9,21)$. However, this aspect is not relevant to the current study setting as all hospitals included in the study were situated in places with convenient access, where all routine postnatal services were delivered free of charge. Further, mothers who have already delivered in institutions were included in the study, thus geographical access was not relevant in this study.

The factors extracted in other studies assessing the validity of client perception instruments have shown varying amounts of total variance of items, ranging from $44 \%(8)$ to $73 \%(9)$. The three factors extracted by EFA in the current study explained $58.9 \%$ of the variance; indicating that around $60 \%$ of the total variance is attributable to these three factors.

The technical care and information domain has accounted for most of the variance explained by the three factors. This depicts that mothers consider receipt of proper care and adequate information as the 
most important component of care, as their primary concern is provision of optimum care for their babies. However, some studies have reported interpersonal care being more important for mothers than this aspect (21).

Ensuring reliability of an instrument provides stability to the instrument. The ward facilities and cleanliness domain obtained a minimum score of 0.82 . Cronbach's alpha value is specific to the study sample used, and therefore cannot be applied to other samples. Yet, there is consistency among studies assessing client perceptions and satisfaction, where domains related physical facilities have obtained lower reliability values than other domains $(8-9,22)$. This may be attributed to the fact that physical facilities are less inter-related compared to the other dimensions of client perceived quality care.

Test retest reliability assessment for the instrument signified a good temporal stability. Cronin and Taylor (1992) suggests that perceived service quality is an attitude that will persist for a longer period (23), which may explain the high Spearman's rank correlation coefficient value. It also indicates that mothers' responses were not significantly affected by courtesy bias as the interviews were conducted as exit interviews at the hospital setting. Accordingly, the developed instrument is suitable to assess client perceptions on institutional postnatal care received following normal vaginal delivery.

A few limitations were identified in this study. As this instrument was specifically developed to measure client perceptions in specialized care institutions in the government sector, it may not be possible to use the same instrument to evaluate the care provided by the primary care institutions or in the private sector. Further, only mothers who have had normal vaginal delivery were included in the instrument development. The experience of mothers who had complicated deliveries may differ significantly from them as the care and monitoring may differ for normal deliveries than mothers who had complicated deliveries (2). Therefore, the instrument may not provide an accurate output if used to assess the perceptions of the quality of care received by mothers with complicated deliveries.

\section{Conclusions \& Recommendations}

The instrument developed for assessment of the maternal perceptions on the quality of care provided following normal vaginal delivery in hospitals in the government sector reported adequate level of validity and reliability. It can be used for improving care provision.

\section{Public Health Implications}

This study established validity and reliability of a newly developed instrument to assess the client perceived quality of institutional postnatal care. The instrument can be used by health institutions to obtain a feedback from postpartum mothers on the quality of the services received, as perceived by them, which is an important component in the assessment of quality of healthcare. This feedback can be used to meet the expectations of mothers and will have direct implications on maternal satisfaction of the services.

\section{Author Declarations}

Competing interests: Authors declare that they have no conflicts of interests.

Ethics approval and consent to participate: Ethics clearance for the study was obtained from the Ethics Review Committee, University of Colombo, Sri Lanka (Reference No: EC-15-098)

\section{Funding: None}

Acknowledgements: Authors would like to acknowledge the support given by the committee of experts during the development phase of the instrument.

Author contributions: SW was the principal investigator and was involved in designing the study, development of the study instrument and conducting the statistical analysis. WG and NH were the supervisors and provided the technical guidance and did the overall supervision. SW drafted the manuscript and $\mathrm{WG}$ and $\mathrm{NH}$ did proof reading and modified the article. 


\section{References}

1. Singh A, Padmadas SS, Mishra US, Pallikadavath S, Johnson FA, Matthews Z. Socio-economic inequalities in the use of postnatal care in India. PLOS One 2012; 7(5): e37037.

2. WHO. WHO Technical Consultation on Postpartum and Postnatal Care. Geneva: World Health Organization, 2010.

3. Al-assafAF, Pierce P, Al-hussein K. A Practice Based Handbook on Healthcare Quality (2 ${ }^{\text {nd }}$ Edition). Istanbul: Turkish Standards Institute, 2009.

4. Castle NG, Brown J, Hepner KA, Hays RD. Review of the literature on survey instruments used to collect data on hospital patients' perceptions of care. Health Services Research 2005; 40(6 II): 1996-2017.

5. Vuori H. Patient satisfaction - an attribute or indicator of the quality of care? Quality Review Bulletin 1987; 13: 106-108.

6. Williams B. Patient satisfaction: A valid concept? Social Science \& Medicine 1994; 38(4): 509-516.

7. Campbell SM, Roland MO, Buetow SA. Defining quality of care. Social Science \& Medicine 2000; 51(11): 1611-1625.

8. van Duong D, Binns CW, Lee AH, Hipgrave DB. Measuring client-perceived quality of maternity services in rural Vietnam. International Journal for Quality in Health Care 2004; 16(6): 447-452.

9. Wijesinghe SD \& Fernando DN. Maternal Perceptions of Quality of Antenatal Care Services in Sri Lanka: Development and Validation of a Multi-dimensional Instrument. International Journal of Interdisciplinary and Multidisciplinary Studies 2014; 1(10): 171-179.

10. Hulton AL, Matthews Z, Stones RW. A Framework for Quality of Care in Maternity Services. Southampton: University of Southampton, 2000.

11. Medical Statistics Unit. Annual Health Bulletin 2014, Sri Lanka. Colombo: Ministry of Health, 2016.

12. Tancred T, Schellenberg J, Marchant T. Using mixed methods to evaluate perceived quality of care in southern Tanzania. International Journal for Quality in Health Care 2016; 28(2): 233-239.
13. Redding CA, Maddock JE, Rossi JS. The sequential approach to measurement of health behaviour constructs: Issues in selecting and developing measures. Californian Journal of Health Promotion 2006; 4(1): 83-101.

14. Comrey AL, Lee HB. A first course in factor analysis ( $2^{\text {nd }}$ edition). New York: Routledge, 1992. Available from: https://www.taylorfrancis.com/books/ 9781315827506.

15. Cronbach LJ, Meehl, PE. Construct validity in psychological tests. Psychological Bulletin. 1955; 52(4): 281-302.

16. Nunnally JC, Bernstein IH. Psychometric Theory ( $3^{\text {rd }}$ edition). New York: McGraw-Hill, 1994.

17. Streiner DL, Norman GR. Health Measurement Scales: A Practical Guide to their Development and Use ( $3^{\text {rd }}$ edition). New York: Oxford University Press, 2003.

18. Rose S, Spinks N, Canhoto AI. Tests for the assumption that a variable is normally distributed. Management research: applying the principles. New York: Routledge, 2015.

19. Abramson JH, Abramson ZH. Survey methods in Community Medicine ( $5^{\text {th }}$ edition $)$. London: Churchill Livingstone, 1999.

20. DeVillis RF. Scale development: Theory and applications ( $2^{\text {nd }}$ edition). Thousand Oaks: Sage Publications, 2003.

21. Srivastava A, Avan B, Rajbangshi P, Bhattacharyya $S$. Determinants of women's satisfaction with maternal health care: a review of literature. BMC Pregnancy \& Childbirth. 2015; 15:97.

22. Haddad S, Fournier P, Potvin L. Measuring lay people's perceptions of the quality of primary health care services in developing countries. Validation of a 20-item scale. International Journal for Quality in Health Care 1998; 10(2): 93-104.

23. Cronin JJ, Taylor SA. Measuring quality: a reexaminations and extension. Journal of Marketing 1992; 56(3): 55-68. 